\title{
DOES IMPORT PARITY PRICING CONSTITUTE EVIDENCE OF EXCESSIVE PRICING AND WHAT ARE THE CONSEPUENCES OF ATTEMPTING TO REMEDY IT?
}

\author{
Richard Murgatroyd* \\ RBB Economics \\ richard.murgatroyd@rbbecon.com \\ Simon Baker\# \\ RBB Economics \\ simon.baker@rbbecon.com
}

April 2011

\begin{abstract}
Although provisions prohibiting abuses of dominance through the setting of excessive prices have long been present under many competition jurisdictions, prohibitions have been seldom applied in practice. This is most likely due to the profound conceptual and practical difficulties in differentiating between pricing conduct that is neutral from a competition law perspective and conduct that genuinely constitutes excessive pricing, and then further problems in remedying genuine abuses. However, recent developments in South African competition policy have focussed on use of import parity pricing as a possible indicator of excessive pricing, although in our view the mere existence of import parity pricing is unlikely to be a reliable indicator of such conduct. This paper draws upon economic theory and relevant jurisprudence to provide clarity as to the circumstances under which import parity pricing might reflect excessive pricing. It then considers the prospects for effective remedies if an abuse is identified.
\end{abstract}

Keywords

Excessive pricing, dominance, imports, pricing, import parity pricing, competition policy, antitrust, remedy

* Mr Richard Murgatroyd is a partner at RBB Economics, South Africa.

\# Mr Simon Baker is a partner at RBB Economics, South Africa. 


\section{EXCESSIVE PRICING ABUSES UNDER COMPETITION LAW}

As under $\varepsilon C$ law, and in common with many other jurisdictions, South African competition law contains a provision prohibiting the abuse of dominance through the exploitation of market power, notably the setting of excessive prices. However, in many of those other jurisdictions, successfully prosecuted excessive pricing cases are extremely rare, and in the US there is no provision at all for the prosecution of conduct that solely involves excessive pricing.

As pointed out by Lyons (2007), this general hostility towards the prosecution of excessive pricing is somewhat paradoxical. This paradox arises from the contrast between the extensive efforts typically made by competition agencies to prevent the exclusionary acts which can lead to the acquisition or maintenance of the market power required to exploit consumers through excessive prices (wherein lies the eventual welfare harm from exclusionary acts) and the far less extensive efforts apparently made to prevent excessive pricing by those already in possession of enduring market power.

The explanation of this seemingly perverse allocation of regulatory effort arises from the immense conceptual and practical difficulties involved in the identification of excessive prices and the associated problems of framing suitable remedies. These problems are extensively discussed in Evans and Padilla (2005), and lead them to the conclusion that there is no costbased or profitability-based test for excessive pricing which is both objective and efficient. They in turn argue that, other than in a very limited set of exceptional circumstances, any level of pricing by dominant firms should therefore be per se legal, due to the very substantial welfare costs likely to flow from the false prosecutions that would inevitably arise. The exceptional circumstances which Evans and Padilla identify are those of a legally protected near monopoly, which is not the result of past investment or innovation, with prices that are much greater than average total cost, and there is a risk that those prices may inhibit the creation of new goods and services in adjacent markets.

Lyons (2007) shares the view that there are profound problems in identifying excessive pricing and acknowledges the potential costs of mistaken intervention against benignly high prices. However, he considers that antitrust authorities still have a role to play in prohibitions of excessive pricing. He believes that they should intervene with the greatest caution and goes on to argue that even in those limit cases in which it may be appropriate to intervene, it would not be appropriate to impose financial penalties.

South Africa joined the excessive pricing debate with the Competition Tribunal (Tribunal) decision in Harmony/Mittal (2007), the first such case brought before it under the South African Competition Act (1998). A central feature of that case was that the domestic prices charged by Mittal South Africa (Mittal) were at import parity (i.e. the price at which the lowest cost internationally produced equivalent steel could be bought, shipped, distributed and sold to South African customers) and these prices were deemed to be excessive.

In addition, in its recent investigation of the fertiliser market, import parity pricing (IPP) was once more a key issue. The conduct of Sasol in the market for ammonia-based fertilisers was allegedly abusive, in part, as it was designed to underpin the import parity pricing of ammonia, of which Sasol was the only domestic producer, and that those import parity prices were allegedly excessive.

These cases indicate a potentially greater willingness on the part of the South African competition agencies to engage in excessive pricing cases than has recently been the case in 
other countries and is an approach which Roberts (2008) suggests may be justified by the history and nature of the South African economy as compared to other jurisdictions.

Moreover, although price discrimination and the inferences that can be drawn from it are widely discussed in the excessive pricing literature, IPP, per se, is not often explicitly discussed. However, given the relatively isolated nature of the South African economy and the significant cost differences consequently seen between domestic suppliers and imports, it is a concept that is likely to continue to play an influential role in South African excessive pricing cases going forward.

This paper applies simple price theory to the different situations under which import parity pricing may arise, with a view to identifying what can and cannot legitimately be inferred about the excessiveness of such prices in each case. It then discusses the prospects for imposing remedies in those situations where it is found that prices have genuinely risen to import parity as a result of a firm pricing excessively.

In particular, while it is clearly desirable to prevent firms from pricing excessively, it is nevertheless important to realise that effective welfare enhancing solutions may not be easy to identify or implement. This is due not only to problems in identifying the competitive price level in the first place, but also because excessive pricing is an abuse borne from the rational desire to maximise profits. The abuse itself therefore provides no guidance as to how it should be remedied, nor is it obvious how a firm might avoid anti-trust scrutiny or, in the absence of an imposed remedy, adjust its behaviour to avoid committing a repeat offence. Moreover, even where a remedy is identified, difficulties in implementation and the potential for knock on effects in other markets mean that overall consumer welfare will not necessarily be improved.

\section{AN OVERVIEW OF IMPORT PARITY PRICING}

IPP essentially describes the situation where a domestic supplier of a particular good sets the price of that good at the level its customers would pay if they were to purchase that good from an importer. It is of course important to recognise that while abstract discussions surrounding IPP typically centre around importing from a world market into a domestic market, the core concepts apply irrespective of the scope of the geographic markets concerned.

Of course, as the competition concerns arising from IPP are likely to stem from a concerns that such prices are excessive, the South African Competition Act (1998) indicates that IPP will be seen as abusive when those prices do not reflect the underlying economic value of the product or service in question and is in excess of that value. The underlying cause for concern behind IPP is therefore that it may be indicative of firms having been able to increase prices to the extent to which they no longer bear relation to the economic value of the product in question.

This line of reasoning is readily apparent in the Harmony/Mittal (2007) matter, where Mittal was found to have priced domestic sales of flat steel at import parity, while pricing product for export at the much lower price of export parity. Harmony Gold Fields argued that in effect the export parity price (the price that a domestic firm must sell at in order to be competitive in the export market) constituted the economic value of the product, and hence the price on domestic sales was excessive. The Tribunal ultimately found that Mittal had engaged in excessive pricing. In particular, the Tribunal noted that Mittal's use of an import parity price was not likely to reflect competitive market conditions, but rather those of monopoly: 
"The point is that both the import parity price or the basket of international commodities are targeted because of their close approximation to the monopolist's profit maximising price."

Although successfully appealed by Mittal before the Competition Appeal Court (2009), and then settled without further precedent being laid down, it is clear on the basis of the discussion in the previous section that IPP is likely to continue to play a significant role in the thinking of the South African competition authorities. Moreover, this is not entirely without economic foundation in so much as IPP may result from firms engaging in excessive pricing. The import parity price will naturally provide a limit to the extent to which firms can increase prices above competitive levels since if prices were increased beyond import parity customers would simply purchase imports for all of their requirements instead. IPP may thus conceivably reflect firms having raised prices above competitive levels, such that even though imports would not have been a viable alternative for customers at competitive price levels, they become a viable alternative at prevailing price levels.

However, it is important to recognise that the mere existence of IPP cannot be considered a sufficient condition for a finding of excessive pricing, nor in fact can it be considered a necessary condition since an excessive price could, as a matter of economic theory, lie below import parity. Rather what matters is how the situation of IPP has been arrived at, which in turn relates to the underlying economics of the matter at hand. Put another way, while IPP may reflect excessive pricing in certain circumstances, the two are not intrinsically linked, as we demonstrate below.

\section{REASONS FOR IMPORT PARITY PRICING}

As discussed above, it is important to recognise that IPP is not synonymous with anticompetitive behaviour but may be indicative of excessive pricing in certain circumstances. This point is demonstrated through a series of examples below.

\section{EXAMPLE 1: IPP with perfect competition and excess demand}

Consider a scenario whereby:

- domestic competition is perfect and atomistic, i.e. there are many small firms that are price takers and do not possess economies of scale;

- total domestic capacity, i.e. the capacities of all domestic firms combined, is $X$;

- domestic firms and their customers are both in the same location (i.e. locations are homogeneous) and hence there is no transport cost between them;

- customers can source imported product at the world price, $P_{w}$, but have to also pay a transport cost of $T$ in order to do so;

- domestic firms face a marginal cost of $C$, which is below the import parity price;

- domestic firms are unable to price discriminate on domestic sales (although they may charge a different price for exports); and

- domestic demand exceeds domestic capacity if prices are at import parity, in this case $P_{w}+T$ (e.g. due to capacity constraints).

The equilibrium outcome of this scenario is illustrated in FIGURE $\mathbf{l}$ below. The figure indicates that if domestic firms supply into the market at a price equal to marginal cost, $C$ there will be excess demand irrespective of their level of capacity utilisation. For example, even if domestic firms operate at full capacity the price customers will be willing to pay, $P^{\prime}$, is far in excess of 
marginal cost. This excess demand places upwards pressure upon prices, which cannot be alleviated by an expansion in domestic supply since suppliers are already operating at full capacity, until imports become a viable alternative for customers, i.e. customers become indifferent between sourcing domestically (if output were available) or from imports. This in turn gives rise to a market price equal to import parity and total market demand of $Q_{I P P}$, of which $X$ is be met by domestic production and the remainder met by imports.

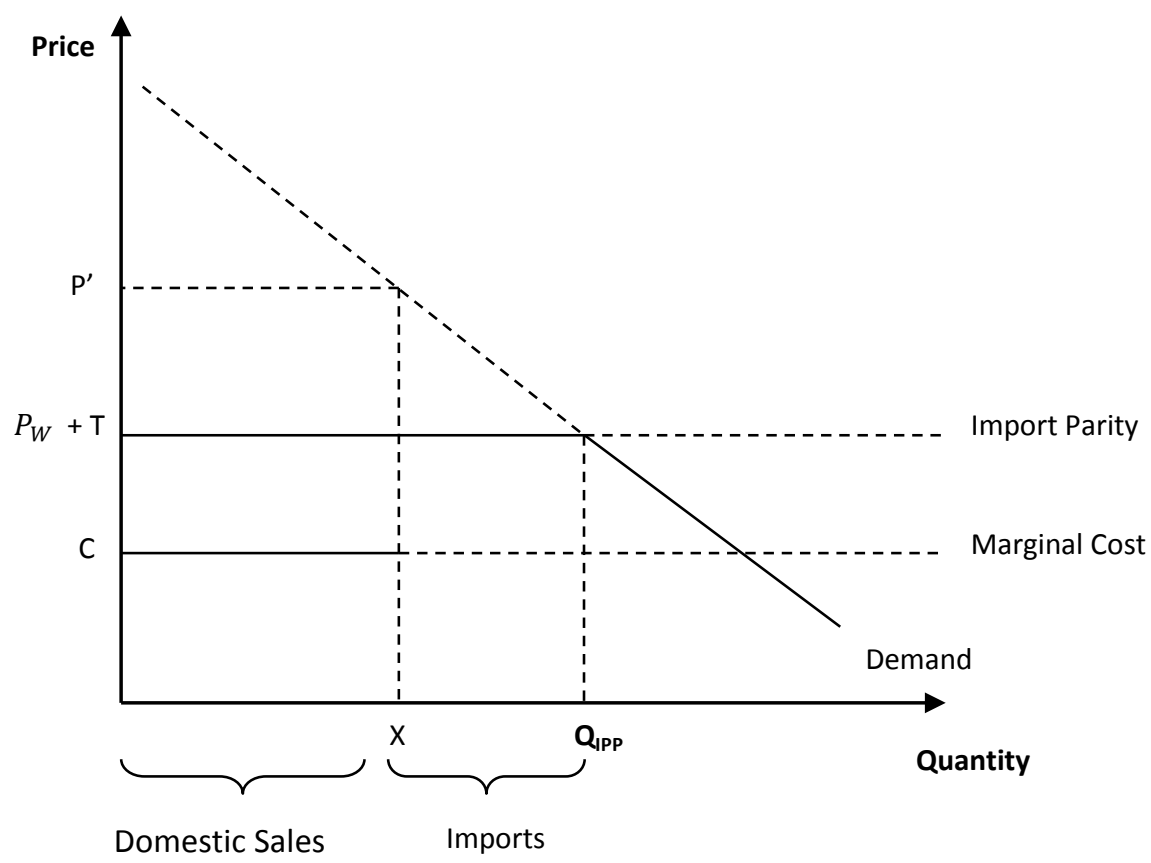

\section{FIGURE 1: IPP with excess demand and perfect competition}

\section{Source: Derived from economic first principles}

In the above scenario we therefore have a market price at import parity even though firms are price takers. This clearly does not equate to excessive pricing since the actions of domestic suppliers have had no effect on equilibrium total output or prices. In addition, it is notable that despite this, domestic firms may nevertheless be able to earn returns in excess of their economic cost of capital, as a result of the locational advantage that they enjoy, and such returns may persist if further domestic entry cannot occur.

This result is of course hardly surprising since one would not normally associate competition concerns with markets that comprise a large number of small price taking firms and thus lean towards the text book perfect competition paradigm. Indeed, competition concerns are typically reserved for those markets comprising of either one firm or a small number of large firms. The underlying rationale for this is that large firms may not be price takers (although structural indicators are often a poor measure of this), but rather appreciate that their own actions may affect market prices. Consider for example the situation where an increase in market supply by a single unit will result in a market price reduction. A price taking firm will supply that additional unit of output provided the price it will obtain for that unit is above the marginal cost of producing that unit, in other words if that additional unit is in and of itself profitable. 
Divergently, a firm that is not a price taker will only supply an additional unit of output if the profit made on that additional unit is sufficient to offset the reduced revenues earned on its existing sales base resulting from a lower market price. Firms that are not price takers may thus find it rational to produce a lower level of output compared to the case if they were price takers.

Put more technically, in a perfectly competitive market the market price and corresponding level of output will be determined according to where the market supply/marginal cost curve intersects with the demand curve, while, for example, under monopoly the market price and corresponding level of output will be determined by where the supply/marginal cost curve intersects with the monopolist's marginal revenue curve, which may in turn result in a higher market price and lower market output. This is essentially the standard monopoly pricing problem, and is illustrated in FIGURE 2 below. Namely, while under perfect competition the market price will be $P_{C}$ and correspond to the level of output $Q_{C}$, under monopoly, output will be restricted to $Q_{M}$ thus inflating the market price to $P_{M}$.

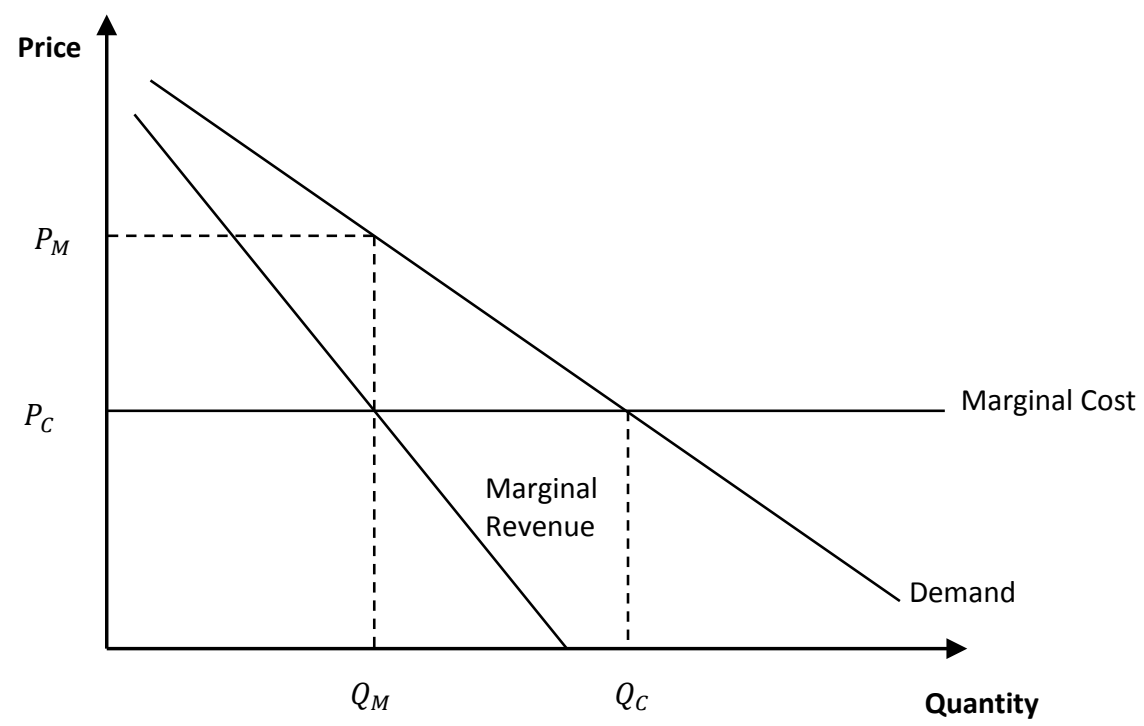

\section{FIGURE 2: Output restriction under monopoly}

\section{Source: Derived from economic first principles}

However, while the above provides a theoretical basis for competition concerns in concentrated markets, even where market structures are highly concentrated, whether or not IPP is likely to be indicative of excessive pricing will still depend upon the specific characteristics of the market in question. This point is illustrated in EXAMPLES 2 and $\mathbf{3}$.

\section{EXAMPLE 2: IPP with a single domestic supplier and excess demand}

Consider a scenario identical to that described in EXAMPLE 1 above, but where instead of a large number of small domestic suppliers with combined capacity of $X$, there is one domestic supplier with a capacity of $X$. However, since the monopolist is unable to meet market demand even when producing at full capacity the market price is set by the marginal supplier to the market, namely imports. At the import parity price the monopolist supplies the entirety of its output, $X$, with the remainder of demand again being made up of imports. 
The key factor driving this result is illustrated in FIGURE 3. The figure demonstrates that because of the ability of consumers to import at the import parity price, the monopolist does not face the same demand and marginal revenue curves as it did in EXAMPLE 1 (marked in dashed lines in the figure below). Instead, the monopolist only faces these curves beyond an output level of $Q_{I P P}$ since at all lower levels of output the monopolist will not face any demand (and hence marginal revenue) at all unless it prices at IPP, i.e. both demand and marginal revenue are zero if the monopolist prices above IPP, while if it prices at IPP these are constant at all levels of output below $Q_{I P P}$. It should be noted that the kinked nature of the demand curve results in a discontinuity in the marginal revenue curve at the output level corresponding to the import parity price.

Crucially then, since demand exceeds domestic capacity at the import parity price, the domestic monopolist does not possess sufficient capacity to be able to operate in the downward sloping section of its demand curve. There is thus no scope for the domestic monopolist to affect price through varying its output and hence despite being a domestic monopolist that firm is nevertheless a price taker.

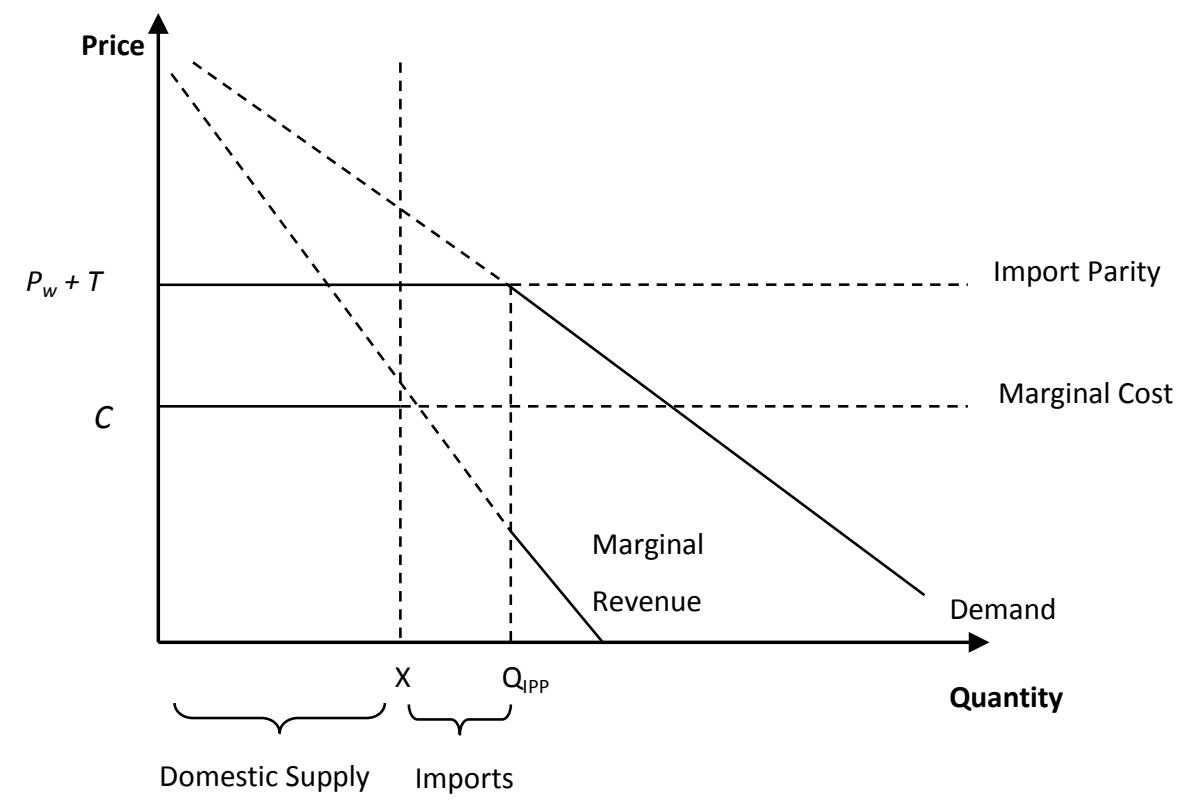

\section{FIGURE 3: IPP with excess demand and domestic monopoly}

\section{Source: Derived from economic first principles}

In this scenario, the domestic firm may again accrue returns in excess of its economic cost of capital, but only as a result of its location and not as a result of any contraction in output. Despite being a local monopolist, the firm has no role in setting the market price and hence IPP again stems from entirely competitive market behaviour. As an aside, this also highlights how structural indicators are often not useful when one is seeking to identify competition concerns.

Both examples outlined above therefore indicate that the existence of excess demand over domestic supply at IPP is a sufficient condition to reject the hypothesis that IPP constitutes excessive pricing. 


\section{EXAMPLE 3: IPP with a single domestic supplier and excess domestic capacity}

Now consider a situation identical in every way to that described in EXAMPLE 2, save for the fact that instead of demand exceeding domestic capacity when prices are at import parity, the domestic monopolist possesses more than enough capacity to meet domestic demand when prices are at import parity.

In this situation, as illustrated in FIGURE 4, the range of output over which the domestic monopolist can produce now includes the downwards sloping section of its, and the market's, demand curve, and hence the domestic monopolist possesses the ability to affect the market price over a subset of its total output range. The domestic monopolist will thus produce up to the point where marginal revenue earned on an additional unit of output is equal to the marginal cost of producing that unit. In this case, since the marginal cost curve intersects the marginal revenue curve at the discontinuity in the curve, this results in an output of $\mathrm{Q}_{I P P}$ and a market price of import parity.

Consumers are thus clearly worse off compared to the case of perfect competition where domestic firms would supply up to the point where marginal cost curve cuts the demand curve (price equals marginal cost), and one would observe a higher output of $Q_{\mathrm{C}}$ and a lower price of $P_{\mathrm{C}}$. In short, since the firm appreciates the effect of its output decision on the market price, it restricts output below the level that would prevail under perfect competition.

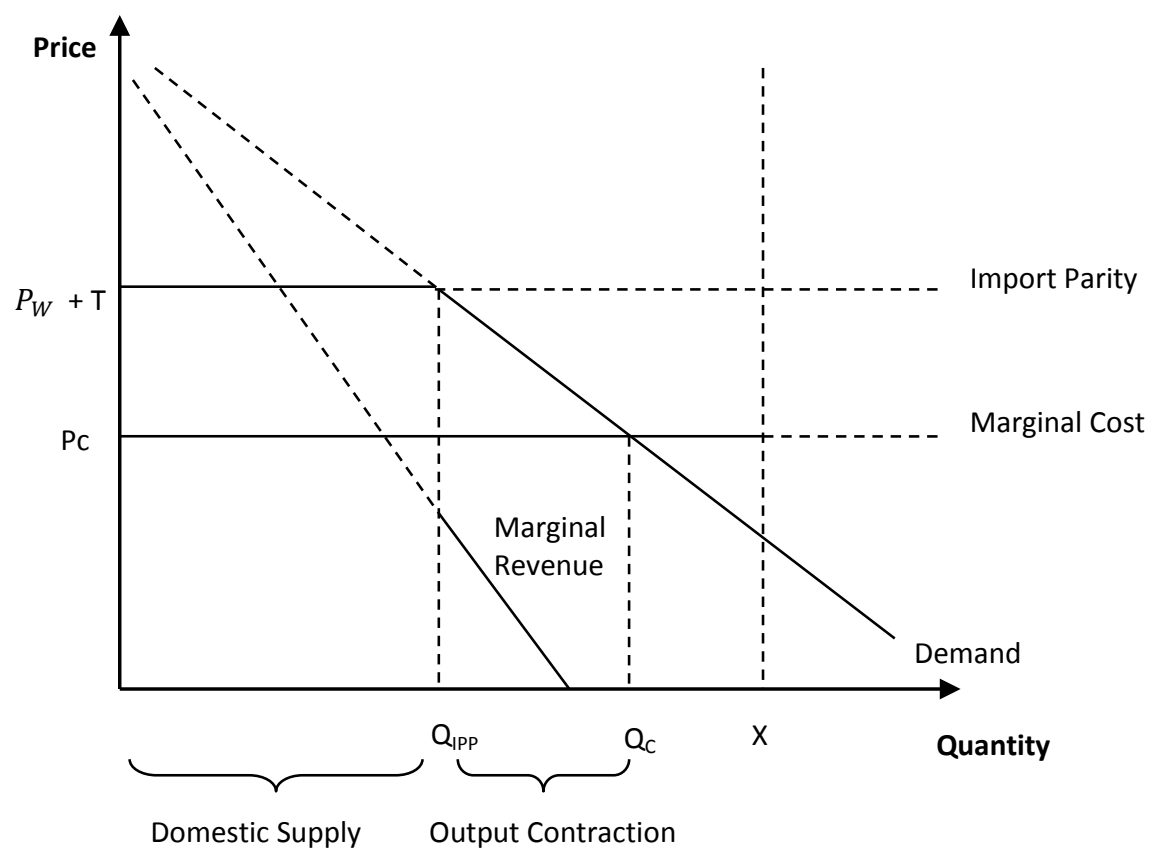

FIGURE 4: IPP with excess capacity and domestic monopoly

Source: Derived from economic first principles

The above example embodies the key distinction between situations whereby domestic pricing at import parity has arisen simply as a result of competitive conditions, and where domestic pricing at import parity has arisen because of behaviour that could be deemed anti-competitive, 
namely whether or not domestic output has been actively restricted to push prices up to import parity. In other words, whether the firm has market power, and whether it has used that market power to reduce output and thus increase prices.

A firm may achieve such a reduction either through an outright restriction of output, as highlighted above, by refraining from selling its entire output domestically, in its primary market, and instead selling some of its output in a secondary market (often described as shorting) or in more dynamic settings by under-investing in productive capacity, relative to a firm behaving competitively, in the face of growing demand and hence restricting future output indirectly (we do not consider this latter possibility in more detail in this paper due to the inherent difficulties in identifying hypothetical investments that were not made in practice but would have nevertheless have been incrementally profitable).

The above examples demonstrate that the range of scenarios where IPP may be associated with excessive pricing will be naturally limited to those where there exists excess domestic capacity, and consequently situations where domestic capacity is insufficient to meet demand at IPP are likely to be entirely benign from an excessive pricing perspective. However, whilst a finding of excess domestic capacity is likely to constitute a necessary condition for a finding of excessive pricing when prices are at import parity, it is not a sufficient condition.

We discuss the reasons for this in more detail below, although a clear example is the case where the domestic monopolist is only able to generate a normal return on capital when its profit maximising domestic price is at IPP. By definition, any lower price would be unable to generate a normal return and hence such a price cannot be seen as a sustainable competitive price. Any analysis must therefore consider the profitability of the monopolist, with all of the problems that this entails, as discussed by Evans and Padilla (2005).

\section{UNDERSTANDING AND IDENTIFYING EXCESSIVE PRICING}

As described above, the existence of IPP is in and of itself unlikely to provide a reliable indicator of whether or not a firm is charging excessive prices, and that IPP can only be indicative of excessive pricing where it has resulted from firms, by virtue of the market power they enjoy, having increased prices significantly in excess of competitive levels by restricting output, and consequently earning a return in excess of their economic cost of capital. However, identifying whether an output restriction has occurred directly is likely to be extremely difficult, in particular since the competitive price level or corresponding level of output is extremely unlikely to be readily observable, and hence an alternative approach must be adopted.

The most economically tractable means of establishing whether prices are likely to be excessive is to gain a thorough understanding of the prevailing competitive conditions of the market in question and hence determine whether conditions are likely to be conducive to such behaviour. In particular, the extent of barriers to entry is likely to play a key role since if barriers to entry are low then it is highly implausible that a firm would be able to profitably sustain prices above competitive levels. Rather such behaviour would be expected to encourage new entrants to undercut the firm's prices, thus driving prices back to competitive levels. Other factors that may be expected to diminish a firm's ability/incentive to charge excessive prices would include the existence of strong buyers or suppliers.

However, care must of course be taken to distinguish between factors that would exist at competitive prices and those constraints that only arise because the firm in question has 
already raised prices above competitive levels, i.e. as a result of the Cellophane Fallacy (see Whish (2009) for more detail on the Cellophane Fallacy). Moreover, in its review of Harmony/Mittal (2007) the Competition Appeal Court of South Africa (2009) found that such a structural assessment was not sufficient to identify excessive pricing. This suggests that at best a structural assessment may be used to rule out excessive pricing but not make a definitive finding of the existence of excessive pricing.

In the absence of mitigating structural factors, case precedent identifies two main approaches to establishing empirically whether output has been restricted and hence corresponding prices may be excessive. Firstly, it may be possible to estimate what a competitive price for the product would be using 'comparators', such as the price of the product in alternative geographic markets, the price charged in the same geographic market but to different customers, or cost metrics such as production costs. This approach possesses some intuitive appeal, and indeed has been adopted in a number of prominent competition matters such as Deutsche Post AG (2001) and United Brands (1978). However, it is important to remember that the use of comparators will only be valid to the extent to which appropriate comparators can be identified.

Any analysis that uses cost as an indicator of the competitive price level, for example, will necessarily be sensitive to which cost elements are included, which is rarely uncontentious. While in some markets it may be relevant to focus on variable costs only, in others it may be relevant to also consider semi-variable or fixed costs, or opportunity costs. Where such an analysis does seek to include all costs relevant to a firm when setting prices, it may become increasingly similar to a profitability analysis (which is addressed separately below). Similarly, there may be good reasons as to why prices charged by a firm in two different markets or to different customers in the same market may be different. An obvious reason is that the costs of serving the different markets or customers may be different, although even if the underlying cost of serving two markets/customers is similar, comparisons may be rendered problematic because demand conditions may be fundamentally different.

Moreover, and perhaps most fundamentally, comparators, particularly when based on alternative prices, may fail to identify if the firm in question is making excess profits, which is important as one could conceivably believe a firm to be charging prices deemed excessive on the basis of a comparator analysis, but at the same time find the firm to be only just covering economic costs. Expecting a firm to lower prices to a level at which it is loss making will be ultimately self-defeating since in the long term that firm will exit the market or be forced to scale back its operations. This shares some common ground with the arguments put forward by Mittal, which argued that the only way it was able to make normal profits was to price discriminate by selling domestically at IPP and exporting at EPP (in fact Mittal argued that not even normal profits were being earned).

Indeed, the theoretical basis for this point holds more generally in so much as firms that incur significant on-going fixed costs may need to price discriminate in order to produce sufficient output to cover them. Assuming Mittal was only earning normal profits in this situation, if, for instance, Mittal was then required to price its domestic output at EPP as well, then it may well be that the large difference between IPP and EPP would render Mittal unable to continue to make normal profits. Similarly, if Mittal were forced to charge a single non-discriminatory price above $\varepsilon P P$, this would prevent Mittal making export sales and may similarly prevent it from earning normal profits.

As such, an alternative approach to the use of comparators, and one that is advocated by Motta and de Streel (2003), is to attempt to infer whether an excessive price is being charged by 
identifying whether the firm in question is able to earn 'excess' profits, i.e. profits in excess of what a firm must be able to earn for it to remain in business in the long term, referred to by economists as 'normal' profits. This approach essentially requires a detailed accounting exercise, although it is important to note that, as described in Davis and Garcés (2010), the concept of normal profit is an economic one that reflects opportunity costs and varying degrees of cost recovery, and is thus often distinct from standard measures of accounting profit. For example, firms may earn high gross profit margins, and thus clearly be profitable in an accounting sense, despite only just being able to cover recurring fixed costs. Implicit here is also therefore the need to value assets in economic terms, which again may differ from accounting valuations in many circumstances. The exercise thus typically requires a comparison of a measure of actual returns with a measure of what might be regarded as a 'normal' return, for example by comparing return on capital employed against weighted average cost of capital.

The underlying rationale behind establishing whether a firm is earning profits in excess of normal profits is reasonably straightforward. Notwithstanding the fact that in theory inefficient firms may charge excessive prices but not earn excess profits as a result of their inefficiency, if an efficient firm is able to earn excess profits this will encourage entry or intensified competition from actual or potential competitors, such that firm's excess profits will be competed away over time (leaving only normal profit). Where excess profits persist over time this may suggest that conventional competitive pressures are not present and that firms may therefore be able to charge excessive prices. Profitability analysis thus provides a natural complement to the more qualitative analysis advocated at the start of this section. However, while it would seem to make sense for the earning of excess profits to be a necessary condition for the finding of excessive pricing, there may be alternative explanations for a firm earning excess profits other than excessive pricing.

First, problems in appropriately capturing economic costs and the values of assets may result in the spurious identification of excess profits. For example, the accounting data typically used in such exercises may inadequately capture the value of intangible assets such as brands and may not adequately reflect risk. Second, even where genuine excess profits are observed these profits may simply be transitory and derived from replicable advantages such as innovation, cost savings and other replicable efficiencies. The earning of such profits should clearly not be deterred since they provide an incentive for firms to replicate the advantages from which they are derived, thus enhancing competition. Third, even if excess profits are enduring they may have no adverse consequences for consumer welfare and hence should not be considered indicative of excessive pricing. Most obviously, and as noted above, if excess profits are derived from the existence of excess domestic demand and not as a result of domestic output restrictions on the part of the domestic monopolist, these cannot be considered to be indicative of excessive pricing.

Therefore in order for excess profits to be indicative of excessive pricing they must be measured correctly to reflect to economic profits, be non-transitory and have arisen from situations where the domestic monopolist has actively sought to restrict domestic output. In order to establish excessive pricing it is therefore necessary to not only establish the existence of excess profits, but also to establish that these excessive profits are as a result of excessive pricing and not some other pro-competitive, benign, or welfare neutral reason. This is consistent with more recent developments in European case law, as summarised in Calcagno and Walker (2010).

Of course, the approaches outlined above not only possess subjective elements but are likely to require significant economic analysis, and thus are not of much assistance to firms and their 
advisors as to whether economic analysis is required in the first place. This is ultimately because the underlying economics surrounding excessive pricing and import parity does not lend itself well to prima facie indicators. However, we have nevertheless sought to provide a nonexhaustive list of potentially informative indicators, namely:

- Domestic capacity compared to total domestic demand-Aside from situations where the domestic monopolist has deliberately underinvested in capacity (which is likely to be extremely difficult to identify in practice for the reasons described above), if domestic productive capacity is not sufficient to meet domestic demand at the import parity price then even a domestic monopolist will not be in a position to affect market prices, and hence cannot be engaged in excessive pricing.

- Proportion of IPP accounted for by transport costs - Notwithstanding the fact that IPP may result from entirely competitive circumstances where transport costs are high, if domestic and international suppliers possess the same level of efficiency the lower the transport costs (or indeed other associated costs) incurred to import product as a proportion of the total selling price, the less scope there is for a domestic firm to seek to inflate prices by reducing output. Where transports costs are low therefore, imports may potentially be more likely to provide a constraint at competitive prices as opposed to merely providing a constraint because a domestic firm has increased prices above competitive levels by restricting output.

- Contractual restrictions - Where firms do not possess sufficient control over their output to ensure that the domestic market remains short they may make use of contractual restrictions to achieve this outcome. It is well established as a matter of economic theory that under certain market circumstances a monopolist may not be able to control its output in such a way as to restrict it to the monopoly level. This is described in relevant literature such as Rey and Tirole (2006) as a monopolist's 'commitment problem'. Where such a problem exists a monopolist may engage in practices that seek to eliminate this problem, for example through the use of specific contractual restrictions, and hence where such restrictions exist, and they cannot otherwise be justified, their existence may be indicative of the existence of excessive pricing (although arguably these restrictions are exactly the kind of practices that should be captured already under exclusionary prohibition). However, it is important to note that this is distinct from situations where a firm simply uses a third party to export its product that it could otherwise have exported itself. Indeed, identifying such a situation can be considered no greater an abuse than would the exportation of equivalent volumes by that firm itself.

\section{REMEDYING ANTI-COMPETITIVE OUTCOMES}

Notwithstanding the difficulties in differentiating instances of excessive pricing from other competitively benign or even pro-competitive behaviour, once a genuine case of excessive pricing has been identified attention must then turn to how such behaviour may be effectively remedied. When examining exclusionary abuses of dominance, the finding itself is likely to suggest a relevant remedy for the conduct.

In contrast, excessive pricing, which is an exploitative abuse, arises from firms simply setting prices in a way that maximises their profits. As such, it is not straightforward for firms to alter their behaviour to avoid anti-trust scrutiny, nor is a finding of excessive pricing in and of itself 
often likely to provide guidance as to how it should be remedied. In particular, a finding of excessive pricing gives rise to two interrelated issues. First, there is the need to devise a remedy that prevents the firm in question from pricing excessively in the future. This may in and of itself be no easy task. Second, there is then the need to evaluate whether the remedy will have any knock on effects that are undesirable. These are discussed in further detail below.

\subsection{Feasibility of a remedy}

Since an excessive pricing abuse is essentially the result of a firm having restricted its domestic output either outright or by shorting the market, for a remedy to be truly effective it must give rise to an expansion in domestic output. It is therefore important to draw a distinction between situations where the firm in question has achieved a domestic output reduction simply because of its own internal decision making, and those situations where the firm would have been unable to do so of its own accord and has therefore imposed an external restriction on other market participants. If it was believed that absent the restriction the firm in question would be unable to restrict domestic output, a potential remedy would therefore be to simply prohibit the restriction.

Contrastingly, where firms are in a position to control the level and distribution of their own output the issue of remedies becomes more difficult. It may be tempting to simply impose price regulation on the firm or industry in question, since this allows the regulator to set a lower price to consumers as well as taking the role of price setting out of the hands of the dominant firm, such that if the firm cannot obtain an increase in price by reducing output it will be disinclined from doing so. However, notwithstanding that, as the Tribunal noted in Harmony/Mittal (2007), competition authorities are often reluctant to play the role of price regulator there also exist a number of good reasons, grounded in economics, as to why price regulation of markets may be undesirable.

- First, any market wide reduction in price below the market level will by definition exclude those suppliers for which the decision to supply the market was marginal in the first place. If the price is set at the competitive level one would expect firms to supply the competitive level of output, but if the regulated price is set below the competitive level, which as discussed above is often extremely difficult to identify, this may exclude suppliers to such an extent that the firms remaining in the market will be unable to meet the increased demand at the lower price, creating a shortage. Under a shortage some consumers will benefit from paying lower prices, while some will lose out by not being able to purchase at all, thus the overall effect on consumer welfare may be ambiguous.

- Second, where only the price of the firm found to have been pricing excessively is regulated and there are no restrictions on the re-selling its output, this will simply provide opportunity for intermediaries to purchase at the regulated price and then resell these volumes at higher market prices. Thus rather than the firm's rents being redistributed to consumers they may simply be accrued by these intermediaries. This is of particular relevance when considering a remedy in situations where there is excess domestic demand at IPP, and hence where it is not possible for a domestic supplier to expand output. While, for the reasons provided above, we do not consider that prices in this context should be deemed excessive in any case, all that can be achieved through a pricing remedy in this instance is the redistribution of rents from the firm in question to intermediaries, with no subsequent enhancement to consumer welfare. 
- Third, there is a great deal of economic literature devoted to how price regulation may distort economic incentives and potentially disincentivise other forms of competitive behaviour. For example, firms will have little incentive to seek to differentiate their product offering or innovate if they will be unable to accrue the returns from doing so by charging higher prices.

An alternative approach, more regularly adopted by authorities where possible, is to seek to remedy the problem structurally, typically via divestment of assets. However, in order to give rise to an expansion in output any structural remedy must divide assets in such a way so as will be likely to result in higher total output. Great care must therefore be taken in designing a structural remedy to achieve this, and it may well be the case that, dependent on market conditions, such a remedy may not be possible. For example, an expansion in output will be less likely to occur in situations where the post-remedy entities possess capacity constraints or where, by dividing the firm, significant economies of scale or other efficiencies are lost. Indeed, one could easily envisage a situation where by dividing the firm sufficient scale economies are lost such that market output ends up being lower than before. In addition, there may of course exist a variety of circumstances where a firm simply cannot be divided up.

\subsection{Desirability of a remedy}

Notwithstanding the points raised above regarding the lack of appetite amongst competition authorities to become price regulators, there are two other important reasons why in general remedies may not always be desirable.

- First, it is important to remember that if a regulated price is imposed upon a market that price must be itself monitored and adjusted over time to reflect changing market conditions and dynamics, while adherence to the regulated price must also be monitored. The need for the chosen regulator to employ individuals to undertake these tasks is thus likely to be costly to society as a whole.

- Second, where excessive pricing is borne from a firm deliberately shorting the primary market (the domestic market in the example above) by supplying into a secondary market, a remedy that encourages an expansion of output in the primary market may in certain circumstances result in a reduction in supply to the secondary market. This might occur, for example, if the firm in question was already producing at high capacity utilisation. Where the secondary market is an international market with many suppliers this may have a negligible effect on prices, but where the secondary market is smaller with only a limited number of suppliers, the withdrawal of the firm's output may place upwards pressure on prices in the secondary market, and thus make consumers in that market worse off. Naturally the extent this is a relevant concern for a competition authority will depend upon whether the secondary market lies under its jurisdiction.

\section{CONCLUDING REMARKS}

This paper highlights that although in theory import parity pricing may result from excessive pricing, it is in isolation likely to be a poor indicator of excessive pricing. Rather it is necessary to understand why IPP has resulted, and specifically whether it has occurred purely as a result of competitive market conditions or from a restriction in output below that which would occur 
under competitive conditions. Since it is virtually impossible to directly determine whether prices are excessive on the basis prima facie evidence, a point which works strongly against an "I know it when I see it approach", this distinction can only ultimately be addressed through gaining a thorough understanding of the industry in question, accompanied by relevant empirical analysis. In particular, in order to advance a theory of harm that a firm is engaged in excessive pricing, it is essential to explain as part of that theory why the firm is not subject to competitive pressures and is thus able to charge excessive prices, and indeed demonstrate empirically that prices are indeed likely to be excessive. For the reasons discussed above, this may be no easy task.

Moreover, even when prices are found to be excessive, substantial hurdles are then likely to be encountered when seeking to remedy such behaviour. For instance, and unlike abuses relating to exclusionary behaviour, the nature of the abuse itself is unlikely to provide effective guidance as to how it may be remedied effectively, or indeed from the firm's perspective guidance as to what it should have done differently. While it may be possible in theory and occasionally in practice to remedy excessive pricing, there are likely to exist a number of real world impediments to doing so effectively. Indeed in certain situations it may simply not be possible to affect the firm's behaviour in a way that is not ultimately self-defeating and actually enhances customer welfare. It is thus not entirely surprising that the number of instances where firms have been found to have engaged excessive pricing are few and far between.

\section{LIST OF REFERENCES}

Calcagno, C. \& Walker, M. (2010). Excessive Pricing: Towards Clarity and Economic Coherence. Journal of Competition Law and Economics, 6(4), pp. 891-910.

Case 27/76 United Brands Company and United Brands Continental BV v. Commission (1978). عCR 207; 35n91, 118, 118n27, 499n122.

COMP/C-1/36.915 Deutsche Post AG - Interception of cross-border mail (2001). Official Journal of the European Communities, L $331 / 40$.

Competition Appeal Court of South Africa (2009); Case No: 70/CAC/Apr07.

Competition Tribunal of South Africa (2007); Case No: 13/CR/FEB 04.

Davis, P. \& Garcés, E. (2010). Quantitative Techniques for Competition and Antitrust Analysis. United States: Princeton University Press.

Evans, D. \& Padilla, A. (2005). Excessive Prices: Using Economics to Define Administrable Legal Rules. Journal of Competition Law and Economics, 1(1), pp. 97-122.

Lyons, B. (2007). The Paradox of the Exclusion of Exploitative Abuse. Centre for Competition Policy Working Paper 08-1.

Motta, M. \& De Streel, A. (2003). Exploitative and Exclusionary Excessive Prices in EU Law. Eighth Annual European Union Competition Workshop (presented).

Republic of South Africa Competition Act (1998).

Roberts, S. (2008). Assessing Excessive Pricing: The Case of Flat Steel in South Africa. Journal of Competition Law and Economics, 4(3), pp. 871-891. 


\section{Murgatroyd \& Baker}

Whish, R. (2009). Competition Law, Sixth Edition. Gosport, Hampshire, Great Britain: Oxford University Press. 